\title{
Um olhar para a produção de pesquisa em educação ambiental a partir do GT Ambiente, Sociedade e Educação, da ANPPAS
}

\author{
Maria Rita Avanzi ${ }^{1}$ \\ Isabel Cristina de Moura Carvalho ${ }^{2}$ \\ Luiz Antonio Ferraro Jr. ${ }^{3}$
}

Resumo: Este artigo traz uma sistematização e análise da produção de pesquisa em educação ambiental (EA) a partir do levantamento dos trabalhos apresentados no Grupo de Trabalho (GT) Ambiente, Sociedade e Educação. O GT integra o Encontro da Associação Nacional de Pesquisa e Pós-Graduação em Ambiente e Sociedade (ANPPAS), que ocorre desde 2002 com periodicidade bianual. A análise busca identificar ênfases temáticas e teórico-metodológicas presentes no GT e, dessa forma, contribuir para a reflexão a respeito da produção de pesquisa em EA no âmbito dessa associação.

Palavras-chave: Educação Ambiental, Produção de Pesquisa, GT Ambiente, Sociedade e Educação, ANPPAS.

Abstract: This paper presents a systematization and analysis of the research production in environmental education (EE) by carrying out a survey of the works presented in the Environment, Society and Education Working Group, which is part of the Meeting of the National Postgraduate and Research Association for Environment and Society (ANPPAS). That meeting has been held since 2002 every two years. The analysis seeks to identify thematic, theoretical and methodological emphases in the Working Group and, as a result, to contribute to reflecting on the research production in $\mathrm{EE}$ within such association.

Keywords: Environmental Education, Research Production, Environment, Society and Education Working Group, ANPPAS.

\section{Apresentação}

O presente texto resulta de uma sistematização dos trabalhos apresentados no Grupo de Trabalho (GT) Ambiente, Sociedade e Educação em

1 Bióloga, doutora em Educação, professora do Núcleo de Educação Científica do IB/UnB. Campus Darcy Ribeiro - Prédio novo do IB $-2^{\circ}$ andar, ASA Norte, BrasíliaDF 70910-900 ou rioavanzi@hotmail.com .

2 Psicóloga, doutora em Educação, professora do PPGEDU e da FACED da PUCRS.

3 Engenheiro agrônomo, doutor em Desenvolvimento Sustentável, coordenador do curso de especialização em educação ambiental para a sustentabilidade da UEFS. 
encontros bienais da Associação Nacional de Pós-Graduação e Pesquisa em Ambiente e Sociedade (ANPPAS). O propósito é identificar possíveis ênfases temáticas e teórico-metodológicas presentes no GT e, dessa forma, contribuir para a reflexão a respeito da produção de pesquisa em educação ambiental (EA) na ANPPAS. A partir disso, formulamos algumas indagações dialogando com outros estudos sobre a pesquisa em EA no Brasil.

A educação ambiental tem traçado, nas últimas décadas, um caminho de constituição de um campo político-pedagógico e acadêmico no país, o que se expressa nas práticas sociais e políticas públicas, na realização de grupos de discussão em eventos acadêmicos, na ampliação de sua produção bibliográfica e de teses e dissertações na área (LORENZETTI; DELIZOICOV, 2007; NOVICKI, 2003), além da composição de redes e da realização de fóruns e encontros nacionais e regionais. A constituição desse campo de pesquisa é aqui compreendida como um processo instável e contraditório, marcado por disputas envolvendo não só outros campos e áreas de conhecimento com os quais se inter-relaciona mas também diferentes orientações políticas e referenciais teórico-metodológicos que dão base à ação educativa ambiental.

Este trabalho é compreendido no contexto de outras análises feitas a respeito da produção acadêmica no campo da educação ambiental ${ }^{4}$, de modo que o seu propósito maior é contribuir com estudos a respeito do estado da arte desse campo.

Na busca por identificar possíveis ênfases temáticas e teórico-metodológicas na produção do GT, esta investigação se pauta por algumas questões propostas por Pato, Sá e Catalão (2008): quais sentidos, temas, campos teóricos, práticas metodológicas se anunciam? É possível identificar autores, conceitos teóricos e metodologias dominantes ou a pluralidade é inerente a esta área?

A Associação Nacional de Pós-Graduação e Pesquisa em Ambiente e Sociedade (ANPPAS), criada em $2002^{5}$, busca articular programas e instituições

4 Carvalho; Schmidt (2008); Lorenzetti; Delizoicov (2007); Novicki (2003); Pato, Sá; Catalão (2008); Reigota (2007).

${ }^{5}$ Segundo informações que constam do sítio da associação (consultado em setembro de 2009), participaram da criação os seguintes programas de Pós-graduação: Núcleo de Estudos e Pesquisas Ambientais, da Universidade Estadual de Campinas (NEPAM/UNICAMP); Núcleo de Altos Estudos Amazônicos, da Universidade Federal do Pará (NAEA/UFPA); Centro de Desenvolvimento Sustentável, da Universidade de Brasília (CDS/UnB); CPDA, da Universidade Federal Rural do Rio de Janeiro; Programa de Pós-Graduação Interdisciplinar em Ciências Humanas, da Universidade Federal de Santa Catarina; Doutorado em Meio Ambiente e Desenvolvimento, da Universidade Federal do Paraná; Programa de Mestrado em Ciência Ambiental, da Universidade de São Paulo (PROCAM/USP); Programa Regional de Pós-Graduação em Desenvolvimento e Meio Ambiente (PRODEMA). 
de pesquisa e formação em nível de pós-graduação com foco nas relações entre Ambiente e Sociedade. É uma associação que, desde sua constituição, traz uma proposta interdisciplinar. Em sua gênese, estão as discussões e articulações que tiveram lugar em outros âmbitos acadêmicos, por exemplo, entre pesquisadores e representantes de programas de pós-graduação da área socioambiental, que dialogavam em reuniões acadêmicas como as da Associação Nacional de Pesquisa e Pós-Graduação em Ciências Sociais (ANPOCS). A interlocução nesses espaços levou à organização de uma publicação interinstitucional, a Revista Ambiente \& Sociedade, no segundo semestre de 1997, o que fortaleceu ainda mais a ideia de criação de uma associação própria.

Desde a formação da ANPPAS, foi instituído um Grupo de Trabalho voltado para temas de educação e meio ambiente, que inicialmente recebeu o nome Sociedade da Informação, Educação e Meio Ambiente e a partir do segundo encontro, em 2004, passou a Sociedade, Ambiente e Educação. Os propósitos desse GT, desde sua criação, são explicitados em sua ementa:

Este GT pretende fomentar o debate sobre as concepções e práticas educativas que têm se constituído no campo ambiental, compreendido como espaço complexo de relações sociais, materiais e simbólicas, envolvidas na disputa pelos sentidos sobre a questão ambiental na sociedade contemporânea. Pretende-se contribuir para a explicitação e discussão dos diferentes pressupostos políticos e epistemológicos que fundamentam intervenções sociais de natureza educativa e que concorrem para a construção de uma esfera de conhecimento e ação dita "ambiental", a qual tem buscado legitimar-se como um novo paradigma (interdisciplinar, transversal) válido no campo do conhecimento e da intervenção educativa.

\section{Traçados metodológicos}

Esta pesquisa se desenvolve a partir do contato direto dos pesquisadores/as com a situação investigada, tanto pela observação participante das sessões de apresentação do GT Ambiente, Sociedade e Educação, ocorridas nos encontros da ANPPAS, como pela análise documental dos trabalhos produzidos pelos/as autores/as que constam dos Anais do evento, publicados em CD-ROM. Desenvolve-se com um caráter descritivo que busca verificar como as questões em pauta se manifestam nos trabalhos apresentados e nas interações ocorridas no GT. A metodologia que a embasa é, portanto, a pesquisa qualitativa em educação (BOGDAN; BIKLEN, 1994). 
O período compreendido nesta sistematização refere-se ao III e IV Encontros da ANPPAS, ocorridos em 2006 e 20086, em Brasília. A produção dos três primeiros encontros - 2002, 2004 e 2006 - consta de um estudo desenvolvido por Isabel Carvalho e Letícia Schmidt (2008), com o qual será estabelecido diálogo neste artigo.

Esta análise se baseou na leitura dos trabalhos na íntegra e também nas notas tomadas na ocasião das sessões de apresentação dos trabalhos, portanto, entre os trabalhos selecionados (Tabela 1), foram considerados aqueles apresentados em sessão oral e cujo paper consta dos anais do III e IV Encontros. Ressalta-se que não foram considerados trabalhos selecionados e não apresentados, nem os trabalhos que, embora apresentados, não constassem dos Anais. Dessa forma, do encontro de 2006 foram considerados 13 trabalhos para esta sistematização e do encontro de 2008, 14 trabalhos.

Tabela 1: Panorama dos trabalhos inscritos e selecionados para apresentação no GT Ambiente, Sociedade e Educação no III e IV Encontros da ANPPAS, ocorridos, respectivamente, em 2006 e 2008.

\begin{tabular}{lcc}
\hline Trabalhos & $\mathbf{2 0 0 6}$ & $\mathbf{2 0 0 8}$ \\
\hline Não selecionados & 19 & 45 \\
Selecionados para comunicação oral & 21 & 20 \\
Selecionados para pôster & 10 & 29 \\
\hline TOTAL & $\mathbf{5 0}$ & $\mathbf{9 4}$ \\
\hline
\end{tabular}

Para a sistematização, os trabalhos foram organizados a partir das seguintes urdiduras:

1) Procedência;

2) Temas;

3) Referencial teórico-metodológico;

4) Concepção de educação ambiental.

A partir desses eixos, foram tecidas as tramas do presente artigo, com uma abordagem que procurou captar os sentidos atribuídos pelos/as autores/as aos trabalhos apresentados.

${ }^{6}$ Nos encontros de 2002 e 2004, o GT esteve sob a coordenação de Isabel Cristina de Moura Carvalho e Laís Mourão de Sá. Em 2006, a coordenação esteve com Lais Mourão Sá e Maria Rita Avanzi, e em 2008, com Maria Rita Avanzi, Isabel Carvalho e Luiz Antonio Ferraro Júnior. 


\section{Sistematização}

\section{Procedência}

Para o estudo da procedência dos trabalhos apresentados no GT e que constam dos Anais do evento, foram consideradas: a região geográfica, a natureza da instituição e a titulação dos/as autores/as, definidas com base nos dados do/a primeiro/a autor/a. No caso de o/a autor/a ser aluno/a de pósgraduação em dada instituição e trabalhar em outra, foi considerada a instituição do programa de pós-graduação. Os trabalhos foram organizados por região geográfica, conforme apresentado na Tabela 2.

Tabela 2: Procedência dos trabalhos apresentados em sessão oral do GT Ambiente, Sociedade e Educação no III e IV Encontros da ANPPAS e que constam dos Anais do evento.

\begin{tabular}{l|cc|cc}
\hline \multicolumn{1}{c|}{ Região } & \multicolumn{2}{|c|}{2006} & \multicolumn{2}{c}{$\mathbf{2 0 0 8}$} \\
trabalhos $\left.\mathbf{( n}^{\mathbf{0}}\right)$ & $\mathbf{( \% )}$ & trabalhos $\left.\mathbf{( n}^{\mathbf{0}}\right)$ & $\mathbf{( \% )}$ \\
\hline Sudeste & 7 & 54 & 4 & 29 \\
Centro-Oeste & 3 & 23 & 5 & 36 \\
Sul & 2 & 15 & 2 & 14 \\
Nordeste & 1 & 8 & 1 & 7 \\
Norte & -- & & 2 & 14 \\
\hline \multicolumn{1}{c|}{ TOTAL } & $\mathbf{1 3}$ & $\mathbf{1 0 0}$ & $\mathbf{1 4}$ & $\mathbf{1 0 0}$ \\
\hline
\end{tabular}

Esta sistematização permite observar que de 2006 para 2008 ocorre maior presença da região Centro-Oeste no GT e uma queda na representação da região Sudeste. Nos encontros de 2002 e 2004, o estudo de Carvalho e Schmidt (2008) aponta a predominância de trabalhos da região Sudeste. A região Norte, não representada naqueles dois primeiros encontros, participa com um trabalho na edição de 2006, o qual não foi contabilizado por não constar dos Anais. No encontro de 2008, portanto, é o primeiro registro que temos no GT para a região Norte.

Essas informações sugerem um caráter ainda regionalizado da produção do GT da ANPPAS, com representação por regiões marcada pela cidade-sede do encontro, uma vez que o primeiro e segundo encontros ocorreram em Indaiatuba, no estado de São Paulo, e os encontros de 2006 e 2008 ocorreram em Brasília. Carvalho e Schmidt (2008) apontam também o fato de a ANPPAS ser uma associação recente que nasceu da iniciativa de programas de pósgraduação das regiões Sul e Sudeste.

Cabe, no entanto, contextualizar esta sistematização ora apresentada na produção acadêmica em educação ambiental no Brasil, tal como apontado por investigações que consideram um universo mais amplo de trabalhos 
(CARVALHO; TOMAZELLO; OLIVEIRA， 2009; LORENZETTT; DELIZOICOV, 2007; NOVICKI, 2003). Esses trabalhos ressaltam o acentuado crescimento da produção de dissertações e teses na área de educação ambiental, especialmente a partir de 1990. Lorenzetti e Delizoicov (2007) pautam sua análise pelas dissertações e teses produzidas nessa área em distintos programas de pós-graduação no Brasil no período de 1981 a 2003. Os autores destacam a predominância da região Sudeste $(48,7 \%)$ na produção analisada, seguida da região Sul $(30,3 \%)$. Destacam o fato de a região Norte não apresentar qualquer tese em educação ambiental no período estudado e atribuem essa constatação à concentração de grande número de cursos de pós-graduação na região Sudeste.

Outro elemento analisado no que diz respeito à procedência dos trabalhos refere-se à natureza da instituição, se pública ou privada. Em ambos os encontros da ANPPAS, em 2006 e 2008, constatou-se a predominância de instituições públicas em relação a particulares: 77\% em 2006 e 86\% em 2008. No encontro de 2006, a totalidade das instituições foi representada por universidades e centros universitários, ao passo que em 2008 estavam presentes, além de universidades, uma fundação vinculada à prefeitura de um município e uma escola de administração pública.

Essa predominância de universidades públicas na produção de pesquisa em EA no Brasil é também relatada por outras investigações que têm maior abrangência no que se refere ao número de trabalhos analisados, tais como as apontadas por Carvalho, Tomazello e Oliveira (2009).

Outra informação que nos parece relevante para o estudo da procedência é a titulação e gênero dos/as autores/as. No encontro de 2006, 10 dos 13 trabalhos (77\%) apresentados no GT tinham como primeiro/a autor/a doutores/as ou doutorandos/as. Os demais eram mestres e mestrandos/as. No encontro de 2008, dos 14 trabalhos apresentados, 36\% tinham doutores/as ou doutorandos/as como primeiro/a autor/a; $50 \%$ dos primeiros/as autores/as eram mestres ou mestrandos/as e $14 \%$ eram especialistas. Considerando a totalidade dos trabalhos apresentados nos dois encontros aqui estudados, 78\% dos trabalhos tinham mulheres como primeira autora.

Carvalho, Tomazello e Oliveira (2009) discutem a vinculação entre a produção de pesquisa em EA no país e o sistema de pós-graduação. Problematizam o fato de o expressivo crescimento dos cursos e do número de titulados em mestrado e doutorado não ter sido acompanhado por um aumento proporcional de financiamento para o setor. Outro aspecto levantado é certa tendência uniformizadora imposta pelo sistema de avaliação da pós-graduação. A ênfase na produtividade, no produto e no quantificável e o paper como fim em si mesmo são alguns dos fatores relacionados ao perfil contemporâneo das 
universidades, que poderiam influenciar a produção de pesquisa, em especial na área de educação e de EA.

\section{Temas}

Para averiguar a presença de ênfases temáticas entre os trabalhos apresentados, foram propostas as seguintes categorias:
a) fundamentos da educação ambiental;
b) educação ambiental escolar ${ }^{7}$;
c) formação de professores;
d) educação ambiental não escolar;
e) educação no campo;
f) políticas públicas de educação ambiental;
g) ética ambiental e formação de valores;
h) sentidos e significados atribuídos ao ambiente;
i) educação ambiental e gestão.

A definição dessas categorias baseou-se nos temas mais recorrentes, identificados durante a seleção dos trabalhos e posteriormente refinados na preparação deste artigo, a partir da análise documental e dos registros de observação participante dos trabalhos apresentados no GT.

Um primeiro olhar para os 13 trabalhos que compuseram a produção do GT em 2006 permite o seguinte agrupamento: Fundamentos da educação ambiental (3); EA escolar (4); EA não escolar (5). $\mathrm{O}$ trabalho restante refere-se à produção de um vídeo e desenvolve reflexões a respeito da Ética ambiental e formação de valores.

No entanto, em um rearranjo, poderíamos agrupar no tema Ética ambiental e formação de valores dois outros trabalhos que abordam públicos participantes de iniciativas de coleta seletiva de resíduos sólidos, com enfoque na questão de valores e formação para a cidadania. A propósito, os temas consumo e destinação dos resíduos sólidos estiveram bastante representados no encontro de 2006, com presença marcante em 5 dos 13 trabalhos, a maioria deles (4) categorizada como EA não escolar. Outro trabalho que entrou nessa categoria de EA não escolarizada enfoca a formação de estudantes de graduação para atuar com

7 Ainda que seja conhecida a controvérsia que há nessa categorização "educação escolar/não escolar", "formal/não formal", optamos por assim caracterizar os trabalhos com o intuito de delimitar, em especial, os sujeitos envolvidos na proposta educativa (escolas de um lado, comunidades em geral do outro) e também para dialogar com outras sistematizações a respeito da produção de pesquisa em EA. 
comunidades, em uma abordagem que busca integrar ensino, pesquisa e extensão.

Em Fundamentos da educação ambiental, os trabalhos versam sobre interdisciplinaridade, sobre processos argumentativos e educação emancipatória e sobre concepção de natureza na perspectiva da hermenêutica filosófica.

Entre os trabalhos agrupados na categoria $E A$ em ambientes escolarizados, um deles refere-se à formação de professores, com abordagem para percepção ambiental; outro investiga a elaboração de uma proposta de etnomatemática para o tratamento de temas ambientais e o terceiro discute perspectivas da utilização da linguagem fotográfica em ações de EA com adolescentes de uma escola pública. O quarto trabalho agrupado nessa categoria trata o tema da educação no campo sob o enfoque da pedagogia da alternância.

Em uma primeira sistematização dos trabalhos apresentados no encontro de 2008, podemos atribuir-lhes a seguinte configuração: Fundamentos da educação ambiental (2); EA escolar (3); EA não escolar (5); Políticas públicas de EA (4).

No que se refere aos Fundamentos da $\mathrm{E} A$, os temas abordados buscam estabelecer relação entre o campo da EA com educação permanente, em um dos trabalhos, e com o campo da justiça ambiental, noutro. No que se refere à $E A$ escolar, um dos trabalhos foca os Sentidos e significados atribuidos ao ambiente por professores e alunos de escolas públicas do ensino fundamental; outro busca reconstruir a formação de estudantes de pedagogia de uma universidade federal a partir do sistema de ensino médio. O terceiro trabalho investiga a formação do sujeito do campo desenvolvida por escolas do sistema de ensino e por organizações não governamentais.

A temática da Educação no campo está presente também em outros dois trabalhos, os quais foram agrupados na categoria $E A$ não escolar, pois são iniciativas de extensão universitária desenvolvidas em assentamentos de reforma agrária. Essa categoria se mantém como a que agrega maior número de trabalhos desde a primeira edição do GT da ANPPAS. É interessante notar que, quando comparada com outros eventos acadêmicos, como o Encontro de Pesquisa em Educação Ambiental (EPEA) e o GT 22 da Associação Nacional de Pesquisa e Pós-Graduação em Educação (ANPEd), essa categoria temática não figura como predominante (CARVALHO; SCHMIDT, 20088; KAWASAKI; MATOS; MOTOKANE, 2006).

Considerando os temas dos dois encontros aqui estudados e dos encontros de 2002 e 2004, sistematizados por Carvalho e Schmidt (2008), é possível notar que pela primeira vez no histórico do GT são apresentados

8 As autoras trabalham com a categoria EA popular. 
trabalhos sobre Politicas públicas de EA. Três desses trabalhos enfocam a política de coletivos educadores implementada pelo órgão gestor da Política Nacional de Educação Ambiental (PNEA) entre 2004 e 2008; o quarto analisa as políticas estaduais de EA e sua institucionalização nas secretarias de educação, articulada pela ação de enraizamento da EA pelo órgão gestor.

Cabe destacar que $E A$ e gestão ambiental, que havia constado como tema de um trabalho no I Encontro (Carvalho; Schmidt, 2008) e não teve ocorrência nos dois eventos subsequentes, aparece como tema de dois trabalhos no IV Encontro.

\section{Referencial teórico-metodológico}

Com o intuito de identificar as tendências teórico-metodológicas dos trabalhos, foram listadas suas referências bibliográficas centrais, identificadas com base na importância que assumiam, no texto e na apresentação, para o desenvolvimento das reflexões teóricas e metodológicas ou como referenciais de análise para as experiências de pesquisa narradas.

A partir desse elenco bibliográfico, foi quantificada a ocorrência de cada autor no conjunto de trabalhos, somados os dois encontros. Esse procedimento baseia-se naquele desenvolvido por Pato, Sá e Catalão (2008) e visa um tratamento transversal do campo teórico para além da referência particular de cada trabalho. Foi considerada pertinente para este estudo a utilização das categorias propostas pelas referidas autoras, a saber:
a) Educação Ambiental;
b) Educação;
c) Construção do conhecimento;
d) Articulações entre ecologia, cultura, política e meio ambiente;
e) Abordagens metodológicas.

\section{Autores/as referenciados/as em educação ambiental}

Os/as autores/as referenciados/as com maior frequência no conjunto de trabalhos dos encontros de 2006 e 2008 são: Isabel C. M. Carvalho (7 trabalhos), Mauro Guimarães (5), Carlos F. B. Loureiro (4), Marcos Sorrentino (3) e Philippe P. Layrargues (3). Esses/as autores/as têm sido apontados/as como referência a uma abordagem crítica e emancipatória da EA.

Vários/as outros/as autores/as, que constam de outras pesquisas sobre o estado da arte em EA, recebem referências pontuais nesse universo de análise. No total, 35 autores/as foram citados como referência para o campo da EA, 
entre eles: Irineu Tamaio, Gustavo Lima, Pedro Jacobi e Marília F. Tozoni-Reis, cada um citado ao menos em dois trabalhos.

\section{Autores/as relacionados/as às teorias da educação}

Considerados os dois encontros, entre os 27 trabalhos que compõem esta sistematização, apenas 10 fazem referência a autores/as relacionados/as às teorias da educação, em um total de 22 autores/as citados/as.

O autor mais citado é Paulo Freire (8 trabalhos); há ainda citações pontuais (em apenas 1 trabalho) de autores como J.J. Rousseau, L. Vygotsky, D. Ausubel, M. Apple, G. Pineau, D. Saviani, U. D’Ambrosio, M. Arroyo, entre outros. Essa presença marcante da pedagogia freireana nos trabalhos de EA já foi identificada por outras pesquisas que analisam os trabalhos do EPEA (CAVALARI; SANTANA; CARVALHO, 2006) e do GT 22 da ANPEd (PATO; SÁ; CATALÃO, 2008).

\section{Teorias acionadas nos trabalhos de $\mathrm{E} A$}

Autores/as relacionados/as à teoria da complexidade, em especial Edgar Morin, são frequentemente evocados nos trabalhos de EA. Outras teorias acionadas são: epistemologia ambiental, hermenêutica, representação social, construção social do conhecimento, racionalismo, pensamento complexo, modernidade, pós-modernidade, sociologia de redes e multiculturalismo.

Os autores que aparecem como referências principais são Enrique Leff (6 trabalhos), Boaventura de Sousa Santos (5), Edgar Morin (2) e Martin Heidegger (2). Os três primeiros são também apontados como referências principais nos trabalhos apresentados no GT da ANPEd (PATO; SÁ; CATALÃO, 2008). Esse recorte teórico de alguns trabalhos sugere o reconhecimento de múltiplos saberes, produzindo condições específicas (multidisciplinares, interdisciplinares) para a constituição de uma epistemologia ambiental.

\section{Articulações entre ecologia, cultura, politica e meio ambiente}

Os trabalhos analisados recebem contribuições de várias áreas do conhecimento consideradas fundamento para a compreensão e intervenção nas questões ambientais. As principais referências são: Ignacy Sachs (3 trabalhos); Ulrich Beck, Anthony Giddens e Scott Lash (2); Hannah Arendt (2); Pedro Demo (2); Juan Bordenave (2) e Milton Santos (2).

Houve 34 autores/as citados/as nos trabalhos analisados. Esses autores estiveram relacionados às seguintes categorias, identificadas por Pato, Sá e Catalão (2008): a) Democracia, participação, políticas públicas e movimentos 
sociais; b) Globalização, desenvolvimento, crise ambiental; c) Cultura; d) Capitalismo, modernidade e trabalho; e) Questão agrária.

\section{Abordagens metodológicas}

Entre os 27 trabalhos que compõem esta sistematização, 9 trazem de forma explícita a abordagem metodológica das pesquisas desenvolvidas. Cabe lembrar, no entanto, que 5 dos 27 trabalhos são ensaios teóricos.

O método citado com maior frequência é a pesquisa-ação (6 trabalhos), com referência aos autores M. Thiollent (3) e R. Barbier (3), seguida pela pesquisa participante: C. R. Brandão (2), Brandão e Streck (1) e M. F. TozoniReis (1).

É feita referência à abordagem fenomenológica com citação a MerleauPonty (1) e E. Masini (1). Há também menção à pesquisa qualitativa de uma forma mais generalizada, quando são citados/as M. C. Minayo (1) e S. Gamboa (1), e duas referências à observação participante (2), mencionando-se a obra de M. Ludke e M. André (1986).

\section{Concepção de educação ambiental}

Sobre a concepção de educação ambiental, o olhar trazido neste artigo foi construído a partir de leituras dos trabalhos na íntegra, com registro de passagens ou excertos que ofereciam elementos que permitissem compreender a concepção de educação ambiental dos/as autores/as, em diálogo com a matriz teórica acionada. Em alguns casos, esses elementos faziam referência explícita à abordagem de educação ambiental orientadora do trabalho. No entanto, na maioria dos casos, a relação com a EA vem de maneira implícita, através de narrativas sobre o significado filosófico, político, cultural ou social do processo educativo e/ou da temática ambiental, além de suas finalidades e objetivos e da metodologia utilizada.

Esta sistematização não tem a pretensão de propor uma taxonomia; trata-se apenas de uma análise qualitativa preliminar, que indica tendências e pontos que chamam a atenção no universo pesquisado, sem esgotar todas as possibilidades.

\section{EA como campo de produção/articulação de uma epistemologia ambiental}

São trabalhos que tomam a EA como espaço/lugar/campo de articulação/construção de saberes ambientais, produção de novos saberes, reconbecimento de múltiplos saberes, diálogo de saberes, produzindo condições específicas (multidisciplinares, interdisciplinares, etc.) para uma epistemologia ambiental, também denominada em alguns trabalhos epistemologia socioambiental. São trabalhos que usaram como referenciais teóricos Leff, Morin e B. S. Santos. 


\section{EA como educação crítico-reflexiva}

Trabalhos que destacam a EA como formação de consciência, hábitos e atitudes ambientais associados a um processo de tomada de consciência sobre as relações social, política, cultural e econômica. Valores como reconbecimento da diversidade cultural, participação, consciência política, ações articuladas e coletivas, empoderamento e reinvenção da democracia aparecem nesse eixo.

Há trabalhos em que a criticidade é destacada como alavanca para a redução de danos e para um melhor gerenciamento ambiental. Esses enfocam a mudança de atitudes em relação ao ambiente calcada na racionalidade e na otimização de recursos. Tratam de busca de alternativas; construção coletiva de propostas; definição de áreas de atuação e responsabilidades; reciprocidade entre a gerência do sistema e a sociedade beneficiada; participação da comunidade no processo de reaproveitamento de resíduos.

\section{EA como educação para o lugar}

Trabalhos que abordam a EA como compreensão das relações entre sociedade e natureza em contextos culturais e ambientais específicos - sertão, grupo de mulheres, populações tradicionais -, com foco nas relações com o lugar, a partir da escola ou fora dela. Incluem as abordagens biorregionalistas e antropológicas, em que a comunidade e suas relações ambientais são o foco da EA, com valorização das ações locais.

\section{EA como educação para a sustentabilidade}

Trabalhos que usam o conceito de sustentabilidade para definir e situar a EA como base para a constituição de elementos de sustentabilidade no nível da formação de consciência e julgamentos sociais. Essa concepção abrange trabalhos relacionados à justiça ambiental.

Há um conjunto importante de trabalhos que tem por foco o desenvolvimento humano no sentido da responsabilidade e do cuidado. São trabalhos que tratam de ética; consciência; consumo; cuidado; mudança de postura do individuo em relação à sua coletividade e ao meio ambiente; ligação/interação/interdependência que possuem todas as coisas; construção de laços empáticos com o ambiente; princípio da responsabilidade com a vida e o planeta; superação do individualismo.

\section{Considerações Finais}

A produção do GT da ANPPAS está ancorada predominantemente em programas de pós-graduação de universidades públicas, com representação marcante de mulheres doutoras/doutorandas e, no último encontro, de mestres/mestrandas. No que se refere à procedência geográfica dos trabalhos, 
nota-se uma predominância da região Sudeste nos 3 primeiros encontros, com maior presença da região Centro-Oeste na última edição. Sem desconsiderar a relação histórica de concentração de cursos de pós-graduação na região Sudeste, cabe problematizar a possível regionalização na participação no GT, marcada pela localização da cidade que sedia o encontro.

Na diversidade temática do GT, ganham expressividade os trabalhos que versam sobre EA não escolar. Contudo, a EA escolar também marcou presença em todas as edições do encontro. A partir de 2008, é notável a presença de trabalhos sobre Políticas públicas de $E A$ relacionados à análise das políticas implementadas pelo órgão gestor da PNEA.

Sobre o referencial teórico-metodológico, autores/as que abordam a EA do ponto de visa crítico e emancipatório são os que aparecem em maior número entre as referências bibliográficas. Outra preocupação que desponta como importante para a pesquisa em EA é a busca por tecer articulações entre áreas de conhecimento como ecologia, política e meio ambiente.

Autores/as relacionados/as às teorias da educação têm presença incipiente entre os trabalhos estudados, e as referências metodológicas são pouco tratadas. Quando aparece referência ao método, predominam as abordagens da pesquisa-ação e pesquisa participante.

É comum o uso de expressões polissêmicas, carregadas de sentidos, mas sem a qualificação do seu entendimento pelo autor. Essa prática dificulta a compreensão dos próprios sentidos atribuídos à EA. Os riscos dessa polissemia estão na falta de clareza e no caráter pouco acessível que os textos assumem. $\mathrm{O}$ enfrentamento disso parece ser um desafio que pode contribuir para as produções acadêmicas em EA.

O termo crítica, repetidamente associado ao fazer da EA, adquire sentidos tanto de elaboração racional quanto de processo que toma a sociedade como objeto, visando seu questionamento. Este último derivado da Teoria Crítica da Sociedade, de Adorno e Horkheimer. Alguns trabalhos associados à abordagem crítica dialogam com autores como Habermas, Boaventura, Beck e outros. Em geral, reforçam a dimensão política da educação. Para qualificar a EA, utilizam expressões como: construção de uma nova sociabilidade emancipatória; formação de sujeitos políticos compromissados com valores libertários, democráticos e solidários; vida democrática de alta intensidade; escassa problematização dos conflitos em muitas das propostas da educação ambiental; promover uma leitura crítica do mundo.

Em alguns casos, é feita uma breve alusão a autores/as ou expressões associadas à abordagem crítica sem estabelecer conexão com as práticas educativas desenvolvidas. A crescente referência a essa concepção nos trabalhos não necessariamente traduz o teor assumido nas práticas de EA Muitas vezes, 
parece ser a projeção de um sentido que se pretende incorporar à prática educativa, ou mesmo a busca por um passaporte para esse campo em constituição.

Este olhar preliminar para a produção da pesquisa em educação ambiental no GT da ANPPAS permite compreendê-la inserida no contexto mais amplo, junto de outros estudos que apontam a EA como um campo multifacetado, marcado por uma pluralidade temática e teórica. Outras pesquisas ressaltam a pouca tradição dos trabalhos de EA de se voltarem para os referenciais teóricos (NOVICKI, 2003; Valentin, 2004). Percebe-se, no entanto, que o GT caminha no sentido de ampliar sua contribuição à produção em pesquisa na área.

\section{Referências}

BOGDAN, Robert; BIKLEN, Sari. Investigação Qualitativa em educação. Porto: Porto, 1994. CARVALHO, Isabel C. de Moura. A questão ambiental e a emergência de um campo de ação político-pedagógica. In: LOUREIRO, Carlos Frederico B.; LAYRARGUES, Phillippe Pomier; CASTRO, Ronaldo Souza de. Sociedade e meio ambiente: a educação ambiental em debate. São Paulo: Cortez, 2000.

CARVALHO, Isabel C. de Moura; SCHMIDT, Letícia. A pesquisa em educação ambiental: uma análise dos trabalhos apresentados na ANPED, ANPPAS E EPEA de 2001 a 2006. Pesquisa em Educação Ambiental, v. 3, p. 147-174, 2008.

CARVALHO, Luiz Marcelo de; TOMAZELLO, Guiomar; OLIVEIRA, Haydée Torres de. Pesquisa em educação Ambiental: Panorama da produção brasileira e alguns de seus dilemas. Cad. CEDES, Campinas, v. 29, n. 77, p. 13-27, jan./abr. 2009.

CAVALARI, Rosa Maria Feiteiro; SANTANA, Luiz Carlos; CARVALHO, Luiz Marcelo de. Concepções de educação ambiental nos trabalhos do I EPEA. Pesquisa em Educaşão Ambiental, São Carlos, v. 1, n. 1, p. 141-173, jul./dez. 2006.

ENCONTRO DA ANPPAS - ASSOCIAÇÃO NACIONAL DE PÓS-GRADUAÇÃO E PESQUISA EM AMBIENTE E SOCIEDADE, 3., 2006, Brasília. Brasília: ANPPAS. (CD-ROM).

ENCONTRO DA ANPPAS - ASSOCIAÇÃO NACIONAL DE PÓS-GRADUAÇÃO E PESQUISA EM AMBIENTE E SOCIEDADE, 4., 2008, Brasília. Brasília: ANPPAS. (CD-ROM). 
KAWASAKI, Clarice Sumi; MATOS, Mauricio dos Santos; MOTOKAME, Marcelo Tadeu. O perfil inicial do pesquisador em Educação Ambiental: elementos para o estudo sobre a constituição de um campo de pesquisa em EA. Pesquisa em Educação Ambiental, São Carlos, v. 1, n. 1, p. 111-140, jul./dez. 2006.

LORENZETTTI, Leonir; DELIZOICOV, Demetrio. A produção acadêmica brasileira em educação ambiental. In: CONGRESO EUROPEO CEISAL DE LATINOAMERICANISTAS, 5., 2007. Bruselas. Disponível em: <http://www.reseauamerique-latine.fr/ceisal-bruxelles/CyT-MA/CyT-MA-2-Lorenzetti.pdf $>$. Acesso em: 28 jul. 2009.

NOVICKI, Vitor. Abordagens teórico-metodológicas na pesquisa discente em educação ambiental: programas de pós-graduação em educação do Rio de Janeiro (1981-2002). REUNIÃO DA ASSOCIAÇÃO NACIONAL DE PÓS-GRADUAÇÃO E PESQUISA EM EDUCAÇÃO, 26., 2003. Poços de Caldas - MG. Disponível em:

<www.anped.org.br/reunioes/26/trabalhos/victordearaujonovicki.rtf>. Acesso em: 13 ago. 2009.

PATO, Claudia; SÁ, Lais Mourão; CATALÃO, Vera Lessa. Mapeamento de tendências na produção acadêmica sobre educação ambiental. In: REUNIÃO DA ANPED, 31., 2008, Caxambu - MG. Disponível em: <http://www.anped.org.br/>. Acesso em: 28 jul. 2009 .

REIGOTA, Marcos. O estado da arte da pesquisa em educação ambiental no Brasil. Pesquisa em Educação Ambiental, Ribeirão Preto, v. 2, n. 1, p. 33-66, jan./jun. 2007.

VALENTIN, Leiri. Tendências das pesquisas em educação ambiental no Brasil: algumas considerações. In: REUNIÃO DA ASSOCIAÇÃO NACIONAL DE PÓSGRADUAÇÃO E PESQUISA EM EDUCAÇÃO, 27., 2004. Caxambu - MG. Disponível em: <http://www.anped.org.br/>. Acesso em: 28 jul. 2009.

Artigo: recebido em 10/11/2009 - aprovado em 21/12/2009 